\title{
Mapping of five candidate sex-determining loci in rainbow trout (Oncorhynchus mykiss)
}

\author{
Mahmoud A Alfaqih ${ }^{1,2}$, Joseph P Brunelli ${ }^{3}$, Robert E Drew ${ }^{4}$ and \\ Gary H Thorgaard*3
}

Address: ${ }^{1}$ School of Molecular Biosciences, Washington State University, Pullman WA 99164-4234, USA, ${ }^{2}$ Department of Pharmacology and Physiology, Mutah University, Karak 61710, Jordan, ${ }^{3}$ School of Biological Sciences and Center for Reproductive Biology, Washington State University, Pullman WA 99164-4236, USA and ${ }^{4}$ University of Idaho, Department of Biological Sciences, Moscow, ID 83844-3051, USA

Email: Mahmoud A Alfaqih - dr_faqih@yahoo.com; Joseph P Brunelli - brunelli@wsu.edu; Robert E Drew - rdrew@uidaho.edu; Gary H Thorgaard* - thorglab@wsu.edu

* Corresponding author

Published: 15 January 2009

BMC Genetics 2009, 10:2 doi:10.1186/1471-2156-10-2
Received: 31 July 2008

Accepted: 15 January 2009

This article is available from: http://www.biomedcentral.com/I47I-2I56/I0/2

(c) 2009 Alfaqih et al; licensee BioMed Central Ltd.

This is an Open Access article distributed under the terms of the Creative Commons Attribution License (http://creativecommons.org/licenses/by/2.0), which permits unrestricted use, distribution, and reproduction in any medium, provided the original work is properly cited.

\begin{abstract}
Background: Rainbow trout have an $X X / X Y$ genetic mechanism of sex determination where males are the heterogametic sex. The homology of the sex-determining gene (SDG) in medaka to Dmrtl suggested that SDGs evolve from downstream genes by gene duplication. Orthologous sequences of the major genes of the mammalian sex determination pathway have been reported in the rainbow trout but the map position for the majority of these genes has not been assigned.
\end{abstract}

Results: Five loci of four candidate genes (Amh, Dax I, Dmrtl and Sox6) were tested for linkage to the $Y$ chromosome of rainbow trout. We exclude the role of all these loci as candidates for the primary SDG in this species. Sox6i and Sox6ii, duplicated copies of Sox6, mapped to homeologous linkage groups 10 and 18 respectively. Genotyping fishes of the OSU $\times$ Arlee mapping family for Sox6i and Sox6ii alleles indicated that Sox6i locus might be deleted in the Arlee lineage.

Conclusion: Additional candidate genes should be tested for their linkage to the $Y$ chromosome. Mapping data of duplicated Sox6 loci supports previously suggested homeology between linkage groups 10 and 18. Enrichment of the rainbow trout genomic map with known gene markers allows map comparisons with other salmonids. Mapping of candidate sex-determining loci is important for analyses of potential autosomal modifiers of sex-determination in rainbow trout.

\section{Background}

Teleost fishes have a variety of evolutionarily labile sexdetermination systems and relatively undifferentiated sex chromosomes [1], and thus are interesting research models for the exploration of how sex-determining mechanisms evolve. The current view of the sex-determination cascade describes it as a gene hierarchy [2]. Genes that reside on top of this hierarchy have been recruited only relatively recently [3] and are only found in specific branches of the phylogenetic tree. Downstream genes are conserved between the different phyla, regardless of the sex-determination mechanism, and thus seem to have been present for a much longer time. The recent discovery that the sex-determining gene of the medaka, Dmy, is a homologue of a downstream gene of the pathway in mammalian species [4] led researchers to propose that downstream genes can be recruited to the top of the hierarchy by gene duplication [5]. This model of evolution of 
the sex-determining gene cascade is further supported in the tilapia model (Oreochromis spp) where the two downstream genes in mammals, Amh and Dmrta2, map within quantitative trait loci, QTL, regions for sex determination in that genus [6].

The salmonid fish, rainbow trout (Oncorhynchus mykiss) has several parallels to the medaka. Both have an XX-XY genetic sex-determination system with the male being the heterogametic sex [7-9] and in both species the sex chromosomes are at an early stage of evolution [8-12]. The sexdetermining mechanism in the rainbow trout is believed to function via a 'dominant' factor located on the Y chromosome as evidenced by the production of XXY triploid males [13]. Dmy, the sex-determining gene in the medaka, also appears to function as a dominant factor. This is supported by male phenotypic development of genetically female (XX) medaka fish injected with a genomic clone containing the Dmy sequence [14].

Based on the proposed model for evolution of sex-determining gene cascades, we hypothesized that in a tetraploid-derived organism like the rainbow trout [15] which has a high repertoire of duplicated genes, any gene in the sex differentiation cascade, or its' homologue, could potentially have evolved as a sex- determining gene. Based on what we currently know from the two sex-determining genes discovered to date in vertebrates, Sry in mammals and Dmy, in the medaka, a sex-determining gene (1) has an upstream position in the cascade, (2) shows stronger expression in male gonads as compared to female, (3) is expressed before sexual differentiation of the gonad and (4) is linked to the Y chromosome. We investigated several candidate genes for sex determination in the rainbow trout model by testing for Y-linkage.

Orthologous sequences of the major genes of the mammalian sex determination pathway have been reported in the rainbow trout; including Wt1, Sox9, Dmrt1, Amh and Dax1. Three Wt1 loci [16], and three Sox9 loci (Alfaqih et al. Submitted) have been previously mapped by our laboratory, but none of the loci were linked to the Y chromosome. In the present study, we tested for linkage of four additional candidate genes for sex determination (Sox6, Dmrt1, Dax1 and Amh) to the Y chromosome of rainbow trout. As we will show, our results have eliminated these loci as candidates for the primary sex-determining gene in the rainbow trout. We also identified a duplication of Sox 6 and discuss the inheritance of the duplicated Sox 6 loci in our mapping families. In addition, we report the complete genomic sequence of Dax1 and a promoter subsequence analysis of Dax1 and Dmrt1 that implicates the role of Pax2 in trout testicular differentiation.

\section{Results and discussion \\ Linkage analysis of Amh, Dax I and Dmrt I}

Through comparison of rainbow trout Amh cDNA sequence with zebrafish (Danio rerio) orthologous genomic sequences, it was determined that the Amh gene of rainbow trout and zebrafish both have six tentative introns. We amplified, cloned and sequenced a $1.35 \mathrm{~kb}$ genomic fragment that contained the $3^{\text {rd }}, 4^{\text {th }}, 5^{\text {th }}$ and $6^{\text {th }}$ introns of $A m h$ from the OSU and Arlee rainbow trout clonal lines (the presence of the $1^{\text {st }}$ and $2^{\text {nd }}$ introns remains tentative and still requires experimental verification). Intron sizes were $337 \mathrm{bp}, 87 \mathrm{bp}, 105 \mathrm{bp}$ and $91 \mathrm{bp}$ respectively. Comparison of OSU and Arlee intron sequences indicated the presence of a SNP in the $5^{\text {th }}$ intron of OSU in a Tsp509I restriction site (Table 1). PCR-RFLP with Tsp509I was used to genotype doubled haploids of the $\mathrm{O} \times \mathrm{A}$ mapping family for receiving either allele. Linkage analysis assigned Amh to linkage group 8 (Figure 1), which corresponds to the short arm of chromosome 5 in the karyotype [17].

Prior to this study, the sequence of the first exon and part of the sequence of the second exon of rainbow trout Dax1 was deposited in nucleotide databases as an expressed sequence tag, EST [Genbank: BX298095]. In order to look for sequence polymorphisms, more likely to be found in non-coding regions of the gene, we isolated and sequenced a complete genomic clone of the Dax1 gene [Genbank: FJ617278]. Tentative locations of the start codon, stop codon and exon-intron boundaries were inferred based on sequence alignment with cDNA sequences of Dax1 from Dicentrarchus labrax [Genbank: AJ633646] and Oreochromis niloticus [Genbank: AY135397] and were not experimentally verified. Our sequence alignment indicated that the coding region of Dax1 contains an ORF of 909 bp and is organized into

Table I: Typing of Amh, Daxl and Dmrtl genes and alleles by sequence polymorphisms in rainbow trout crosses.

\begin{tabular}{llllll}
\hline Gene & Accession numbers & Parent & Site of polymorphism & Polymorphism & Method of genotyping \\
\hline \multirow{2}{*}{ Amh } & F]609190 & Arlee & $82-85$ of fifth intron & AAT(T) & PCR-RFLP Tsp509I \\
& F] 609189 & OSU & $82-85$ of fourth intron & AAT(G) & Taqman assay \\
Daxl & Fj617280 & HC & -10 of 5' UTR & G & A \\
& Fj617279 & OSU & -10 of 5' UTR & GTA(C) & PCR-RFLP Rsal \\
& -- & HC & 743 of first intron & GTA(A) &
\end{tabular}




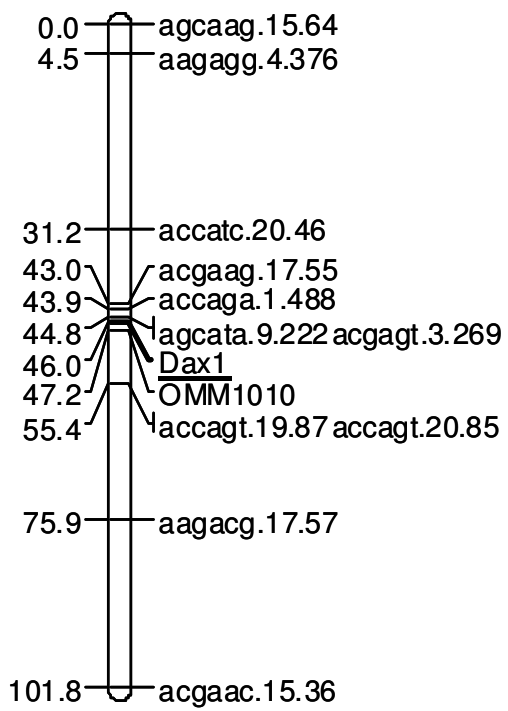

$118.8-$ Omy 1014
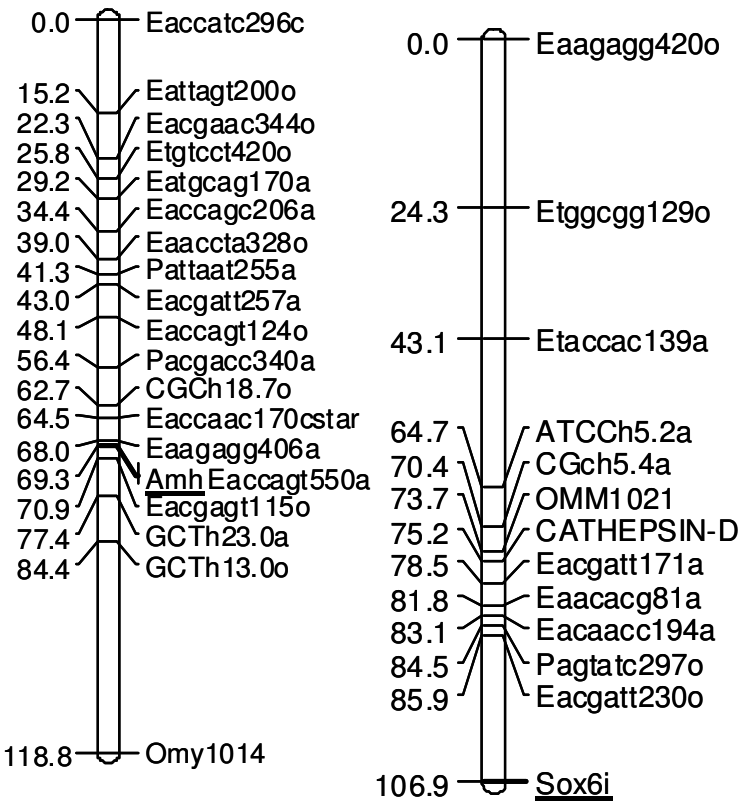

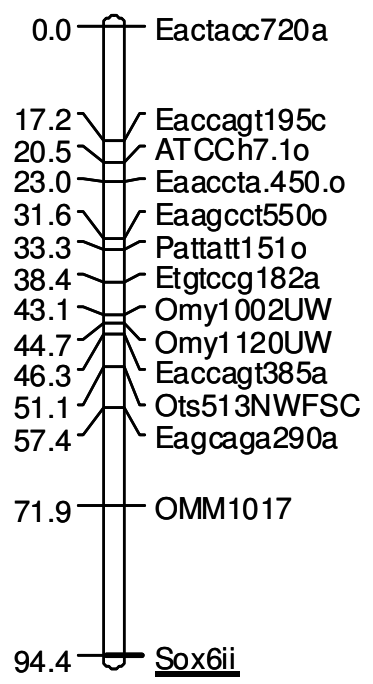

Figure I

Genetic map of rainbow trout (Oncorhynchus mykiss) candidate sex-determining loci. Numbers on the left indicate distances in centimorgans. Marker names are indicated on the right. The linkage group number and the mapping family used for linkage analysis are indicated on top of each linkage group. Candidate sex-determining loci are underlined.

two exons (670 and 239 bp in size respectively) separated by a 560 bp intron. A 303 amino acid polypeptide was deduced from the inferred cDNA sequence.

No polymorphism between parental lines of our mapping family was detected in the intron, thus a $1.1 \mathrm{~kb}$ fragment of the genomic region located upstream to the putative coding sequence of Dax 1 was amplified and sequenced to look for sequence polymorphisms. An (A/G) SNP between OSU and HC parental lines was found in the sequenced region (Table 1 ). Doubled haploids of the $\mathrm{O} \times$ $\mathrm{H}$ mapping family were genotyped for either allele. Genotyping doubled haploids mapped Dax1 to linkage group 5 (Figure 1), which corresponds to the long arm of chromosome 22 on the physical map [17].

Sequence analysis revealed the presence of a SNP between OSU and HC that resulted in the loss of an RsaI site in the $\mathrm{HC}$ allele in a $1.89 \mathrm{~Kb}$ genomic fragment containing the first intron of Dmrt1 (Table 1). PCR-RFLP using Rsa1 restriction was used to genotype doubled haploids of the $\mathrm{O} \times \mathrm{H}$ mapping family for receiving either Dmrt1 allele but linkage analysis was unable to assign Dmrt1 to any linkage group in the $\mathrm{O} \times \mathrm{H}$ map. Chi-square analysis did not support linkage of the HC (YY) Dmrt1 allele with the $\mathrm{Y}$ chromosome of rainbow trout as indicated by phenotypic sex of the doubled haploid fish $(\chi 2=5.241$, d.f. $=3$, $\alpha=0.05)$. One explanation for the failure to map Dmrt1 is the absence of markers closely linked with Dmrt1 in the genetic map. A second explanation would be that a duplicate of this gene may have also been amplified and interfered with accurate genotyping. However, a chi-square test $(\chi 2=2.572$, d.f. $=1, \alpha=0.05)$ did not detect deviation from Mendelian ratios which would likely occur in such a situation.

\section{Promoter Subsequence Analysis of Dax I and Dmrt I}

Subsequence analysis of an upstream $1.2 \mathrm{~Kb}$ promoter sequence of Dax1 [Genbank: FJ617278] and a 649 bp promoter sequence of Dmrt1 [Genbank: FJ617281] identified a number of transcription factor binding sites or cis regulatory elements (Table 2 and Table 3). Some of these elements are binding sites for products of genes known to be involved in the sex differentiation cascade of mammals including elements for SF1 (steroidegenic factor 1), WT1 (Wilms' tumor suppressor), COUP-TF (chicken ovalbumin upstream promoter-transcription factor), HMGA (high mobility group A) and PAX (paired domain box). Experiments in mammalian systems have demonstrated the interaction of the Dax1 gene product with SF1, WT1, and COUP-TF [18-20].

\section{Duplication and linkage analysis of Sox6}

Boundaries of eight putative introns were identified in Sox6 of rainbow trout by comparing the cDNA sequence from rainbow trout to genomic sequences of zebrafish 
Table 2: Promoter sequence analysis of rainbow trout DaxI.

\begin{tabular}{lllc}
\hline Element & Sequence & Location (bp) \\
\hline PAX5 & CTGTAGCACTGAAATGCAGTGCCTTAGAC & $-1096 /-1124$ & Strand \\
SFI & ATCTCAAGGCCAT & $-816 /-828$ & + \\
COUP-TF & CCGAGTGGGGCAGCGGTCTAAGGCA & $-1082 /-1105$ & + \\
HMGA & ACAAATTCACAACTCCC & $-523 /-539$ & - \\
TATA box & TAATATAAATGTGCTGC & $-123 /-139$ \\
WTI & TTGCGCGGGGGTATCAG & $-104 /-119$ & + \\
PAX 2/5/8 & CTTTGAAGAGTTG & $-52 /-63$ & + \\
SOX-5 & TTCTGACAATGCAGTAA & $-488 /-504$ & - \\
\hline
\end{tabular}

Nucleotide positions correspond to the start codon.

(Danio rerio) and fugu (Takifugu rubripes). PCR amplification of the fourth intron of Sox6 from OSU and HC produced two products of differing size in each of the clonal lines. Following cloning and sequencing of all four products, OSU products were determined to be 984 and 1067 bp in size, while the sizes of the recovered products in HC were 984 and 1097 bp (Table 4). Using the BLASTN algorithm, all four sequences were verified to be that of Sox6. The larger-sized OSU and HC alleles were named Sox6i while the smaller-sized alleles were named SoxGii. Sequence analysis of the four different Sox6 alleles in OSU and $\mathrm{HC}$ revealed the presence of a microsatellite repeat nested in the $4^{\text {th }}$ intron. The size difference between Sox6i and SoxGii is due to an expansion in the size of the repeat (Table 4). The size difference between the HC and OSU alleles at Sox6i is due to a 30 bp expansion of the microsatellite repeat in HC. No size or sequence polymorphisms were detected between OSU and HC at SoxGii. The presence of two Sox6 products in each of the homozygous clonal lines (OSU and HC) indicated that Sox6 is duplicated in the rainbow trout.

PCR amplification of the same intron from Arlee produced only one product $984 \mathrm{bp}$ in size. Cloning and sequencing of the product did not show any sequence variants supporting the presence of a second Sox6 allele in Arlee. Sequence comparison revealed a polymorphism between OSU and Arlee parental lines that resulted in the loss of an AvalI restriction site in SoxGii of OSU (Table 4 and Figure 2(A)). PCR-RFLP with AvalI was used to genotype doubled haploids of the $\mathrm{O} \times \mathrm{A}$ mapping family (refer to Materials and Methods under linkage mapping for details on genotyping doubled haploids).

In the $\mathrm{O} \times \mathrm{A}$ mapping family, linkage analysis assigned SoxGi to linkage group 18 (acrocentric chromosome 26) and SoxGii to linkage group 10 (long arm of chromosome 6) supporting their homeology (Figure 1). This relationship was previously suggested by linkage analysis of duplicated microsatellites and by physical mapping of bacterial artificial chromosome (BAC) clones of duplicated loci $[17,21,22]$. Since there were no polymorphisms in the recovered SoxGii sequences between OSU and $\mathrm{HC}$, this allele could not be mapped in the $\mathrm{O} \times \mathrm{H}$ cross. The size polymorphism in SoxGi between OSU and HC allowed us to map this gene to linkage group 18 , in agreement with results from the $\mathrm{O} \times \mathrm{A}$ cross.

\section{Inheritance of Sox $\mathbf{6}$ alleles in the $\mathbf{O} \times \mathbf{A}$ family}

Two models are considered here to explain the inheritance pattern of Sox 6 loci in individuals of the $\mathrm{O} \times \mathrm{A}$ mapping family.

\section{Simple disomic inheritance with identical Sox6 Arlee alleles}

If we assume that Arlee (A) has two identical Sox6 alleles and assume independent assortment and random segregation of OSU and Arlee alleles, four genotype classes should be observed: (1) OSU - Sox6i/OSU - SoxGii (Genotype 1 in figure 2) (2) A - Sox6i/A - Sox6ii (Genotype 2) (3) OSU - Sox6i/A - SoxGii (Genotype 3) (4) A - Sox6i/ OSU - Sox6ii. This last genotype was not observed in the $\mathrm{O} \times \mathrm{A}$ family (figure 2) which raises questions regarding validity of the model.

Table 3: Promoter sequence analysis of rainbow trout Dmrtl.

\begin{tabular}{llll}
\hline Element & Sequence & Location (bp) & Strand \\
\hline SFI & CCTACAAGGTTAC & $-176 /-188$ & - \\
SFI & TTTGCAAGGCCAC & $-438 /-450$ & + \\
PAX2 & CAACTTCTCGCGACATTAAACAC & $-138 /-160$ & + \\
PAX3 & ACTGTCCCACGTGTACTCT & $-187 /-205$ & - \\
PAX6 & ATTAAACACTTCAATAAGA & $-128 /-146$ & + \\
\hline
\end{tabular}

Nucleotide positions correspond to the start codon. 
Table 4: Typing of Sox6 genes and alleles by sequence polymorphisms in rainbow trout crosses.

\begin{tabular}{|c|c|c|c|c|c|c|}
\hline Gene & Accession numbers & parent & Site of polymorphism & Polymorphism & Method of genotyping & Size of marker \\
\hline Sox6ii & EU848567 & Arlee & $725-729$ of fourth intron & G(G)ACC & PCR-RFLP Ava II & 984 bp \\
\hline Sox6i & EU848564 & OSU & $806-810$ of fourth intron & G(G)ACC & & 1067 bp \\
\hline Sox6ii & EU848565 & OSU & 725 of fourth intron & $G(A) A C C$ & & 984 bp \\
\hline Sox6i & EU848568 & $\mathrm{HC}$ & Size of fourth intron & 30 bp expansion & Size polymorphism & 1097 bp \\
\hline Sox6ii & EU848569 & $\mathrm{HC}$ & No polymorphism with Sox6ii of OSU & & & 984 bp \\
\hline
\end{tabular}

\section{Simple disomic inheritance with failure to amplify Sox6i allele} from Arlee

If we assume that primer combination used to amplify different Sox6 loci failed to amplify Sox6i allele in Arlee because of a mismatch in the primer sequence, or because of deletion of Sox6i in the Arlee lineage, Sox6i allele in Arlee can be genotyped as a null allele. Four genotype classes are expected in the $\mathrm{O} \times \mathrm{A}$ progeny if Sox6 $i$ is genotyped as a null allele: (1) OSU - Sox6i/OSU - Sox6ii (Genotype 1 in figure 2) (2) A - null/A - Sox6ii (Genotype 2) (3) OSU - Sox6i/A - Sox6ii (Genotype 3) (4) A -null/OSU - Sox6ii (Genotype 4). Genotype analysis of the $\mathrm{O} \times \mathrm{A}$ mapping family showed that 23 out of 73 doubled hap- loids were of genotype 1, 20 doubled haploids were of genotype 2, another 20 doubled haploids were of genotype 3 and only 9 were of genotype 4 . Chi-square analysis did not show significant deviation of the observed proportions for the different genotype classes from the theoretical proportions expected under this model $\left(\chi^{2}=\right.$ 6.2603, d.f. $=3, \alpha=0.05$ ).

The (A -null/OSU - Sox6ii) genotype can also be explained by failure of the AvaII restriction assays. Genotyping was however confirmed by digestion with NlaIII which also produces a distinctive restriction profile for each of the

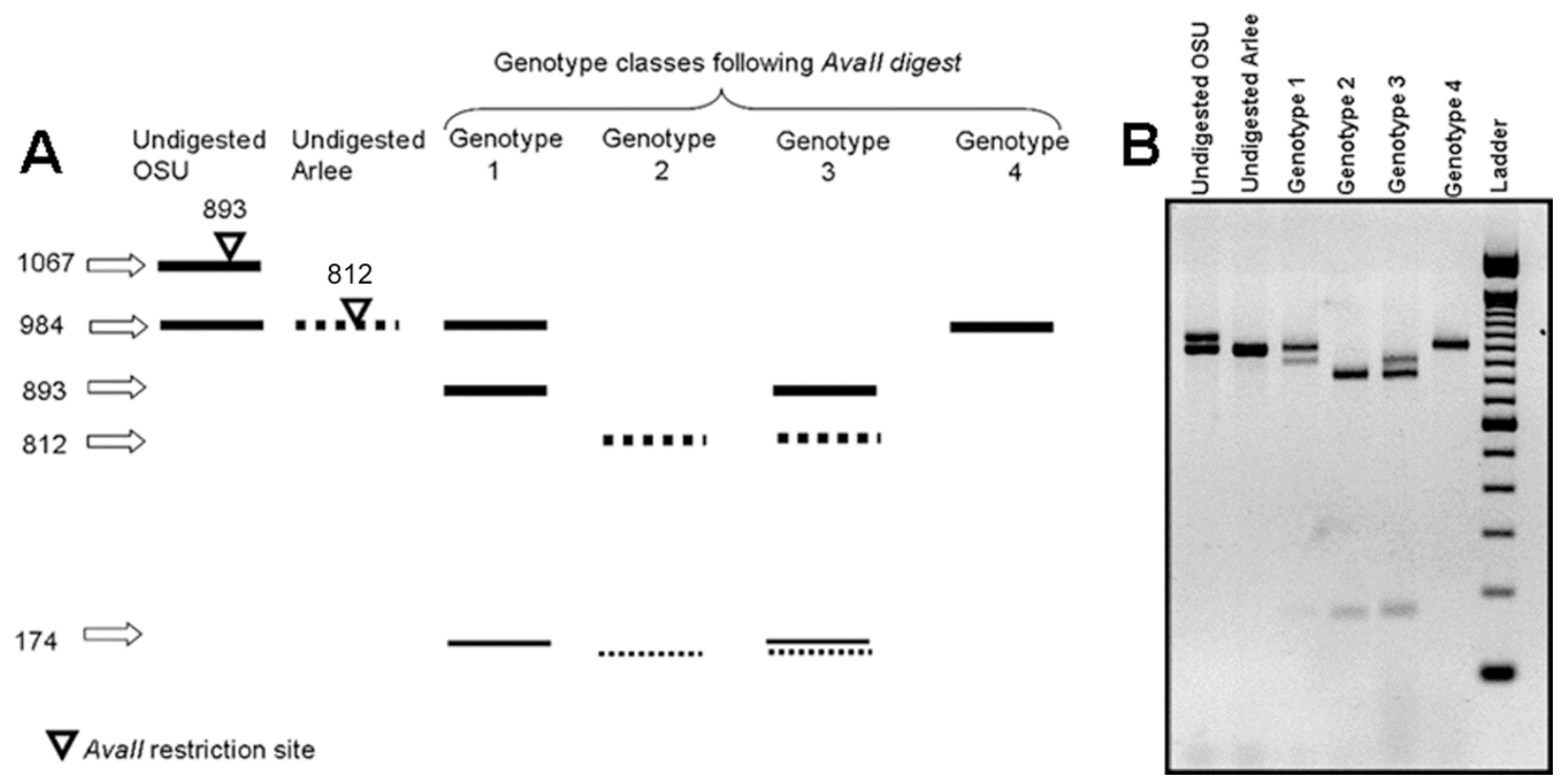

Figure 2

Inheritance of Sox6 alleles in the rainbow trout OSU $\times$ Arlee mapping family. (A) A schematic diagram showing the different Sox6 alleles in OSU and Arlee parental lines and the different genotype classes that were observed in doubled haploids of the OSU $\times$ Arlee mapping family. The OSU alleles are shown in solid lines while the Arlee alleles are shown in dashed lines. Restriction sites of Avall enzyme are indicated by an inverted triangle on each respective Sox6 allele. The distance of each restriction site away from the $5^{\prime}$ end of each respective allele is indicated above the triangle. Sizes of the different Sox 6 alleles before their digestion with Avall and the sizes observed in the mapping family following Avall digestion are indicated with arrows. (B) A $2 \%$ agarose gel image of the different Sox6 alleles in OSU and Arlee parental lines and the different genotype classes observed in doubled haploids created by androgenesis from an OSU $\times$ Arlee hybrid. Look at part (A) for details. 
four genotype classes of the mapping family and thus ruling out this possibility (data not shown).

\section{Additional candidate genes for sex-determination}

We tested five loci for their linkage to the Y chromosome of rainbow trout in this study. In addition, three Sox9 loci (Alfaqih et al. Submitted) and three WT1 loci [16] have also been mapped in rainbow trout. This brings the total number of candidate genes of rainbow trout sex determination tested for linkage to the Y chromosome to eleven. All of the loci tested were chosen based on their role in sex determination in mammals and on expression during testicular differentiation of rainbow trout [23].

A number of candidate genes can still be tested for their linkage to the sex locus of rainbow trout. In mammalian species, ten out of the 30 genes discovered so far in the Sox gene ( $S r y$-related HMG box) family have been shown to be involved in the sex differentiation pathway or expressed in embryonic testes or ovaries [24,25]. Rainbow trout orthologs of five of those genes have been deposited in GENBANK or the TIGR Rainbow Trout Gene Index. Genes of the DM domain (Doublesex and MAB-3 related) family are also strong candidates for sex determination in rainbow trout. There are at least six DM domain genes in fishes, most of them with unknown functions [24,26]. In addition to Dmrt1, orthologous sequences of Dmrt2 and Dmrt4 have been isolated from rainbow trout [27]. Studying the gene expression profile of 102 genes involved in gonadal differentiation of rainbow trout, Baron et al [23] identified Pax $2 a$ as a gene that is expressed early in gonadal development and displays a testis-specific expression profile. Our study identified potential binding sites of Pax2 in the promoter sequences of Dmrt1 and Dax1 suggesting that members of this gene family should be explored in future analyses. Although our analysis focused on candidate genes that already have sequences deposited in public databases, paralogous loci might still be isolated and would also be strong candidates for sex-determination based on the model presented for evolution of sexdetermining systems [2].

It is largely accepted that the sex-determining system in rainbow trout is genetic with male heterogamety. Nonetheless, Quillet et al [28] reported an equal ratio of males and females in a mitotic gynogenetic family. Studying the transmission of maleness of XX gynogenetic fish across the next three generations, the authors concluded that unexpected maleness might be caused by a recessive mutation of a sex-influencing factor carried on an autosomal pair of chromosomes. This conclusion however was not accompanied by any genetic mapping of the causative mutation. Our mapping data of the candidate genes will thus be of great value in analysis of the inheritance of such an autosomal sex-determining factor.

\section{Conclusion}

Using linkage analysis, we excluded the role of five candidate loci as the primary sex-determining gene in rainbow trout. We also identified a duplication of the Sox6 locus. Inheritance pattern of Sox 6 loci in $\mathrm{O} \times \mathrm{A}$ mapping family indicated possible deletion of Sox6i locus in the Arlee lineage. Our mapping data supports previously suggested homeology between linkage groups 10 and 18 in rainbow trout, and adds four known genes to its genomic map. Enrichment of the rainbow trout genomic map with type I markers allows the identification of conserved syntenic blocks between rainbow trout and other salmonid species, which would eventually allow for understanding the molecular organization of genomes following genome duplication. Although we did not find the primary sexdetermining gene in this study, our data is of importance for analyses of potential autosomal modifiers of sex-determination in rainbow trout.

\section{Methods}

\section{Mapping families and linkage maps}

Two mapping families and their respective linkage maps have been used for this study. Mapping families are doubled haploid fish generated from F1 hybrids between two clonal lines using androgenesis. Clonal lines were produced by androgenesis and gynogenesis [29,30]. Each clonal line is homozygous at all loci and its isogenecity has been confirmed by multilocus DNA fingerprinting [31].

OSU $\times$ HC mapping family $(\mathrm{O} \times \mathrm{H})$

This family was produced from the F1 hybrid of the Oregon State University (OSU: XX female) and Hot Creek (HC: YY male) clonal lines. The family was previously described in Zimmerman et al [32] where it was used to identify a single major QTL affecting natural killer cell-like activity. In our study, 85 doubled haploid fish from the original mapping family were genotyped for polymorphisms in non-coding regions of the candidate genes Sox6, Dmrt1 and Dax1.

OSU $\times$ Arlee mapping family $(O \times A)$

This family was produced by androgenesis from a cross between the OSU (XX) and Arlee (AR; YY) clonal lines, previously used to generate a dense linkage map and is described in Young et al [33] and Nichols et al [22]. In our study, 76 doubled haploid fish of the original mapping family were genotyped for polymorphisms in non-coding regions of the candidate genes Sox 6 and Amh. Synteny between the $\mathrm{O} \times \mathrm{H}$ and $\mathrm{O} \times$ A linkage maps has been established [32]. 


\section{Identification of polymorphisms in non-coding regions of candidate genes \\ Primer design}

In order to amplify genomic DNA fragments of non-coding regions of candidate genes, primers were designed to anneal within exons flanking tentative introns. Boundaries between exons and introns were predicted for Sox6, Dmrt1 and Amh through comparisons of their cDNA

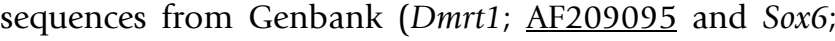
D61688) or TIGR gene index (Amh; TC103383) with genomic sequences of Takifugu rubripes and Danio rerio. Primer sequences are listed in Table 5.

\section{$P C R$ reactions}

All PCR reactions were performed using a Thermolyne Amplitron II thermocycler. PCR reaction conditions began with denaturation at $94^{\circ} \mathrm{C}$ for 2 minutes, followed by 30 cycles of $94^{\circ} \mathrm{C}$ for 45 seconds, $60^{\circ} \mathrm{C}$ for 45 seconds and $72^{\circ} \mathrm{C}$ for 45 seconds. The reaction ended with a final extension step of $72^{\circ} \mathrm{C}$ for 2 minutes. All reactions were $20 \mu \mathrm{l}$ in volume containing: $50 \mathrm{ng}$ DNA template, $1 \times$ PCR buffer (Invitrogen, Carlsbad, CA), $2.5 \mathrm{mM} \mathrm{MgCl}_{2}, 10$ pmoles of each primer, $0.25 \mathrm{mM}$ dNTPs (Invitrogen, Carlsbad, CA) and 1.5 U of Taq DNA Polymerase (Promega, Madison, WI).

Cloning, sequencing and sequence alignments

Following the amplification of non-coding regions of candidate genes, PCR amplification products were resolved in a $2 \%$ agarose gel stained with ethidium bromide. Desired DNA fragments were gel-purified using Gene Clean (Bio 101, Vista, California), cloned into the pGEM-T Easy plas- mid system (Promega, Madison, WI) and then sequenced at the Washington State University Laboratory for Biotechnology and Bioanalysis. Target gene sequence verification was performed using the BLASTN and BLASTX algorithms of the NCBI website. Sequence polymorphisms between parental alleles were identified by aligning them using Sequencher 3.11 software (version 3.1.1; Gene Codes, Ann Arbor, MI). Because cloning can introduce artifact sequence differences, polymorphisms were confirmed by direct sequencing of genomic DNA amplification products using a nested primer (nested primer sequences are not shown).

\section{Isolation of DaxI and Dmrt I genomic sequences}

A PCR-based approach (Brunelli et al. In press) was used to isolate lambda clones of Dax1 and Dmrt1 from a $\lambda$ Zap II (Stratagene, La Jolla, CA) genomic library created from an $\mathrm{O} \times \mathrm{H}$ F1 hybrid. Following sequencing of the Dax1 and Dmrt1 lambda library clones by PCR walking, the structure of the Dax1 gene was deduced based on sequence alignment with the relevant sequences of Dicentrarchus labrax and Oreochromis niloticus. Intron and promoter sequences of Dmrt1 were identified based on alignment of the recovered genomic clone with rainbow trout Dmrt1 published cDNA sequence.

\section{Genotyping of doubled haploid populations PCR-RFLP}

Non-coding sequences of the candidate genes Sox6, Dmrt1 and Amh have sequence substitutions between alleles of the different parental lines that alter recognition sequences of restriction enzymes (RE). Utilizing these dif-

Table 5: Primer sequences for amplifying non-coding regions of candidate sex-determining genes in rainbow trout.

\begin{tabular}{|c|c|c|c|}
\hline Gene & Cloning/Library screening primers & Marker position & Mapping primers \\
\hline \multirow[t]{2}{*}{ Sox6 } & $\begin{array}{l}\text { F: TTCACAGGCAGCAAGACCAG } \\
\text { R: AACAGCGCTGTGGAGTTCAG }\end{array}$ & $4^{\text {th }}$ intron & $\begin{array}{l}\text { MF: TTCACAGGCAGCAAGACCAG } \\
\text { MR: AACAGCGCTGTGGAGTTCAG }\end{array}$ \\
\hline & & & $\begin{array}{l}\text { SF: CTAGAGCTGCGGATGTTGTAAC } \\
\text { SR: TGAGCCCACTGGCAGGTGTTC }\end{array}$ \\
\hline Amh & $\begin{array}{l}\text { F: CATCACTTTCACCAGTCACTC } \\
\text { R: TCGGTACTGCGTCTCACTG }\end{array}$ & $4^{\text {th }}$ intron & $\begin{array}{l}\text { MF: CATCACTTTCACCAGTCACTC } \\
\text { MR: TCGGTACTGCGTCTCACTG }\end{array}$ \\
\hline \multirow[t]{2}{*}{ Daxl } & $\begin{array}{l}\text { LF: CTCCGGTCACCGCAGGTTAC } \\
\text { LR: AGGATCCGTTGCAACATGC }\end{array}$ & 5' UTR & $\begin{array}{l}\text { TF: CGAGCAGCACCCGATGTAG } \\
\text { TR: CCTCGCGAGTGGCCAT }\end{array}$ \\
\hline & $\begin{array}{l}\text { F: ACCTACAGCACCGAATATCAC } \\
\text { R: GTTGTTGCCTTAGCTCAAGC }\end{array}$ & & $\begin{array}{l}\text { P: CACGTGGTGCGCG } \\
\text { P: CACGTGGCGCGCG }\end{array}$ \\
\hline Dmrtl & $\begin{array}{l}\text { F: AGGAACCACGGCTACGTGT } \\
\text { R: CAACCTCCTGACTGGACAG }\end{array}$ & Ist intron & $\begin{array}{l}\text { MF: CAGAAATGCAAACTGATCGC } \\
\text { MR: CAACCTCCTGACTGGACAG }\end{array}$ \\
\hline
\end{tabular}

$F$ and $R$, forward and reverse primers used for amplifying genomic fragments that were later cloned and sequenced; $L F$ and $L R$, forward and reverse primers used for library screening; MF and MR, forward and reverse primers used for mapping each respective fragment; SF and SR; forward and reverse primers used for genotyping by size polymorphisms; TF and TR: forward and reverse primers used for genotyping by Taqman assay. P: Sequences of the probes used for genotyping by Taqman assay. 
ferences, doubled haploid fish of the mapping family were genotyped for the parental allele containing the polymorphic restriction site by PCR amplification, followed by RE digestion. Products of the RE-digest were size-fractionated in $1.5 \%$ agarose gels. Appropriate restriction enzyme digestions were done in $20 \mu \mathrm{l}$ volume reactions according to the manufacturer's directions (New England Bio-labs, Ipswich, MA). Gene-specific primers utilized in RFLP-genotyping are listed in Table 5. Polymorphic REsites are listed in Table 1.

\section{Taqman assay}

A single nucleotide polymorphism (SNP) was detected between OSU and HC in the deduced promoter region of Dax1. The polymorphism did not change any published recognition sequence of a RE. A Taqman assay (Applied Biosystems, Foster city, CA) was used to score doubled haploids of the $\mathrm{O} \times \mathrm{H}$ mapping family for having either OSU or HC alleles. Primers and probe sequences used in the Taqman assay are listed in Table 1.

\section{Microsatellites}

A microsatellite repeat nested in the Sox 6 fourth intron was found to have a different size among the different Sox6 alleles (Table 4). Size differences were large enough to be analyzed in a $2.5 \%$ agarose gel stained by ethidium bromide and viewed under UV light. Primer sequences used for amplifying the microsatellite are listed in Table 5 . Default PCR reaction conditions were used for the amplification.

\section{Linkage mapping}

Prior to linkage analysis, segregation data of all loci was checked for deviations from expected Mendelian ratios using a chi-square test ( $\alpha=0.05$ ). Genotyping data of candidate genes was incorporated into the pre-constructed $\mathrm{O}$ $\times \mathrm{H}$ and $\mathrm{O} \times \mathrm{A}$ linkage maps using Map Maker 3.0/EXP [34]. Marker orders were retained from the previous publications using these families $[22,32]$. For Sox6, doubled haploids were genotyped for receiving OSU Sox6i or Sox6ii alleles, while the Arlee Sox6i allele was genotyped as a null allele. The locations of newly-genotyped loci were determined using the "try" command, with the Kosambi map function, a minimum LOD score of 3.0 and a maximum theta of 0.45 .

\section{Promoter sub-sequence analysis}

A $2.2 \mathrm{~Kb}$ region upstream of Dax 1 and $0.6 \mathrm{~kb}$ region upstream of Dmrt1 coding regions were sequenced from the isolated lambda clones. The promoter sequences were analyzed for the presence of putative regulatory elements for transcription factors known to be involved in sex differentiation using MatInspector software (Genomatix Software GmbH, Munich, Germany).

\section{Authors' contributions}

MA drafted the manuscript, assisted in designing the study, recovered genomic sequences and genotyped doubled haploid fish of reference families. JB assisted in genotyping analyses and provided technical assistance. RD conducted linkage analysis on the reference families. GT conceived the study, participated in its design and coordinated the roles of the authors. All authors read and approved the final manuscript.

\section{Acknowledgements}

This work was supported in part by National Institute of Environmental Health Sciences grant ESO 2446 to James Nagler and by National Research Initiative grant 2006-35205-16728 from the USDA CSREES to Gary Thorgaard and Hubert Schwabl.

\section{References}

I. Devlin RH, Nagahama Y: Sex determination and sex differentiation in fish: an overview of genetic, physiological, and environmental influences. Aquaculture 2002, 208(3-4): $191-364$.

2. Wilkins AS: Moving up the hierarchy: a hypothesis on the evolution of a genetic sex determination pathway. Bioessays 1995, I7(I):7I-77.

3. Marin I, Baker BS: The evolutionary dynamics of sex determination. Science 1998, 28 I(5385): 1990-1994.

4. Matsuda M, Nagahama Y, Shinomiya A, Sato T, Matsuda C, Kobayashi T, Morrey CE, Shibata N, Asakawa S, Shimizu N, et al.: DMY is a Yspecific DM-domain gene required for male development in the medaka fish. Nature 2002, 417(6888):559-563.

5. Schartl M: Sex chromosome evolution in non-mammalian vertebrates. Curr Opin Genet Dev 2004, I 4(6):634-64I.

6. Shirak A, Seroussi E, Cnaani A, Howe AE, Domokhovsky R, Zilberman N, Kocher TD, Hulata G, Ron M: Amh and Dmrta2 genes map to tilapia (Oreochromis spp.) linkage group 23 within quantitative trait locus regions for sex determination. Genetics 2006, 174(3): 1573-158I.

7. Donaldson EM, Hunter GA: Sex control in fish with particular reference to salmonids. Canadian Journal of Fisheries and Aquatic Sciences 1982, 39:99-110.

8. Nanda I, Kondo M, Hornung U, Asakawa S, Winkler C, Shimizu A, Shan Z, Haaf T, Shimizu N, Shima A, et al.: A duplicated copy of DMRTI in the sex-determining region of the $Y$ chromosome of the medaka, Oryzias latipes. Proc Natl Acad Sci USA 2002, 99(18): $11778-11783$

9. Thorgaard $\mathrm{GH}$ : Heteromorphic sex chromosomes in male rainbow trout. Science 1977, 196(4292):900-902.

10. Felip A, Fujiwara A, Young WP, Wheeler PA, Noakes M, Phillips RB, Thorgaard $\mathrm{GH}$ : Polymorphism and differentiation of rainbow trout Y chromosomes. Genome 2004, 47(6): I I05- I I I3.

II. Iturra P, Bagley M, Vergara N, Imbert P, Medrano JF: Development and characterization of DNA sequence OmyP9 associated with the sex chromosomes in rainbow trout. Heredity 200I, 86(Pt 4):412-419.

12. Thorgaard GH: Chromosomal differences among rainbow trout populations. Copeia 1983, 3:650-662.

13. Thorgaard $\mathrm{GH}$, Gall GAE: Adult triploids in a rainbow trout family. Genetics 1979, 93(4):96I-973.

14. Matsuda M, Shinomiya A, Kinoshita M, Suzuki A, Kobayashi T, PaulPrasanth B, Lau E-I, Hamaguchi S, Sakaizumi M, Nagahama Y: DMY gene induces male development in genetically female (XX) medaka fish. Proceedings of the National Academy of Sciences 2007, I04(I0):3865-3870.

15. Allendorf FW, Thorgaard GH: Tetraploidy and the evolution of salmonid fishes. In The Evolutionary Genetics of Fishes New York: Plenum publishing; 1984.

16. Brunelli JP, Robison BD, Thorgaard GH: Ancient and recent duplications of the rainbow trout Wilms' tumor gene. Genome 200I, 44(3):455-462.

17. Phillips RB, Nichols KM, DeKoning JJ, Morasch MR, Keatley KA, Rexroad C 3rd, Gahr SA, Danzmann RG, Drew RE, Thorgaard GH: 
Assignment of rainbow trout linkage groups to specific chromosomes. Genetics 2006, I74(3):166I-1670.

18. Burris TP, Guo WW, Le T, McCabe ERB: Identification of a Putative Steroidogenic Factor-I Response Element in the DAXI Promoter. Biochemical and Biophysical Research Communications 1995, 21 4(2):576-58|.

19. Kim J, Prawitt D, Bardeesy N, Torban E, Vicaner C, Goodyer P, Zabel B, Pelletier J: The Wilms' Tumor Suppressor Gene (wt I) Product Regulates Dax-I Gene Expression during Gonadal Differentiation. Mol Cell Biol 1999, I 9(3):2289-2299.

20. Yu RN, Ito M, Jameson JL: The Murine Dax-I Promoter Is Stimulated by SF-I (Steroidogenic Factor-I) and Inhibited by COUP-TF (Chicken Ovalbumin Upstream Promoter-Transcription Factor) via a Composite Nuclear Receptor-Regulatory Element. Mol Endocrinol 1998, I 2(7): 1010-1022.

21. Guyomard R, Mauger S, Tabet-Canale K, Martineau S, Genet C, Krieg $F$, Quillet $E$ : A type I and type II microsatellite linkage map of rainbow trout (Oncorhynchus mykiss) with presumptive coverage of all chromosome arms. BMC Genomics 2006, 7:302.

22. Nichols KM, Young WP, Danzmann RG, Robison BD, Rexroad C, Noakes M, Phillips RB, Bentzen P, Spies I, Knudsen K, et al.: A consolidated linkage map for rainbow trout (Oncorhynchus mykiss). Anim Genet 2003, 34(2): I02-1 I5.

23. Baron D, Houlgatte R, Fostier A, Guiguen Y: Large-scale temporal gene expression profiling during gonadal differentiation and early gametogenesis in rainbow trout. Biol Reprod 2005, 73(5):959-966.

24. Bowles J, Schepers G, Koopman P: Phylogeny of the SOX family of developmental transcription factors based on sequence and structural indicators. Dev Biol 2000, 227(2):239-255.

25. Takada S, Koopman P: Origin and possible roles of the SOX8 transcription factor gene during sexual development. Cytogenet Genome Res 2003, I0I(3-4):2 12-2I8.

26. Volff JN, Zarkower D, Bardwell V], Schartl M: Evolutionary dynamics of the DM domain gene family in metazoans. J Mol Evol 2003, 57(SuppI I):S24I-249.

27. Marchand O, Govoroun M, D'Cotta H, McMeel O, Lareyre J, Bernot A, Laudet V, Guiguen Y: DMRTI expression during gonadal differentiation and spermatogenesis in the rainbow trout, Oncorhynchus mykiss. Biochim Biophys Acta 2000, I493(I2): $180-187$.

28. Quillet E, Aubard G, Queau I: Mutation in a sex-determining gene in rainbow trout: detection and genetic analysis. J Hered 2002, 93(2):91-99.

29. Parsons JE, Thorgaard GH: Production of androgenetic diploid rainbow trout. J Hered 1985, 76(3): I77-I8I.

30. Scheerer PD, Thorgaard GH, Allendorf FW: Genetic analysis of androgenetic rainbow trout. J Exp Zool I991, 260(3):382-390.

31. Young WP, Wheleer PA, Fields RD, Thorgaard GH: DNA fingerprinting confirms isogenecity of androgenetically derived rainbow trout lines. J Hered 1996, 87:77-8I.

32. Zimmerman AM, Evenhuis JP, Thorgaard GH, Ristow SS: A single major chromosomal region controls natural killer cell-like activity in rainbow trout. Immunogenetics 2004, 55( I 2):825-835.

33. Young WP, Wheeler PA, Coryell VH, Keim P, Thorgaard GH: A detailed linkage map of rainbow trout produced using doubled haploids. Genetics 1998, I48(2):839-850.

34. Lander ES, Green P, Abrahamson J, Barlow A, Daly MJ, Lincoln SE, Newburg L: MAPMAKER: An interactive computer package for constructing primary genetic linkage maps of experimental and natural populations. Genomics 1987, I(2):174-181.
Publish with Biomed Central and every scientist can read your work free of charge

"BioMed Central will be the most significant development for disseminating the results of biomedical research in our lifetime. "

Sir Paul Nurse, Cancer Research UK

Your research papers will be:

- available free of charge to the entire biomedical community

- peer reviewed and published immediately upon acceptance

- cited in PubMed and archived on PubMed Central

- yours - you keep the copyright
BioMedcentral 